\title{
Preliminary Examination of the Accuracy of a Fall Detection Device Embedded into Hearing Instruments
}

\author{
Justin R. Burwinkel ${ }^{1}$ Buye $\mathrm{Xu}^{1} \quad$ Jeff Crukley $^{1}$ \\ ${ }^{1}$ Starkey Hearing Technologies, Eden Prairie, MN \\ J Am Acad Audiol 2020;31:393-403.
}

\author{
Address for correspondence Justin R. Burwinkel, Starkey Hearing \\ Technologies, Eden Prairie, MN 55344 \\ (e-mail: justin_burwinkel@starkey.com).
}

\begin{abstract}
Background Accidental falls are a significant health risk to older adults and patients seen in audiology clinics. Personal emergency response systems are effective in preventing long lies (defined as remaining on the floor or ground for greater than one hour after a fall), but some individuals would prefer to wear less-conspicuous devices than a traditional neck-worn pendant. No previous investigation has compared the accuracy of head-worn fall detection devices with those worn on other parts of the body. In this study, we compared the accuracy of one commonly used fall detection pendant with two variants of a new hearing instrument-based fall detection system. Purpose The purpose of the study was to evaluate the accuracy of detecting falls by using inertial sensors embedded in hearing instruments.

Research Design A study with repeated measures for one group.

Study Sample Ten young adults served as participants. All participants had normal or corrected-to-normal vision during testing. Individuals were excluded if they had selfreported cardiac disorders, recent concussions, or musculoskeletal conditions.

Data Collection and Analysis Data were collected from inertial measurement unit (IMU) sensors, embedded into a binaural set of hearing instruments, during laboratory-based simulations of falls, near-falls, and activities of daily living (ADLs). The detection state of a fall

Keywords

- accelerometry

- accidental falls

- activities of daily living

- adult

- hearing aids and assistive listening devices

- motion detection pendant was simultaneously recorded during performance of each trial and compared with the outputs of offline hearing instrument firmware emulators.

Results One hearing instrument-based fall detection system was more accurate than the fall detection pendant. A second hearing instrument-based fall detection system performed similar to the fall detection pendant. Each of the three fall detection systems investigated were robust against false-positive detections during ADLs.

Conclusions Preliminary findings demonstrate that hearing instruments embedded with a fall detection device (FDD) may be a suitable alternative to more traditional forms of FDDs (e.g., pendant, wrist-worn device, etc.) for detecting falls and potentially preventing long lies.
\end{abstract}

\section{Introduction}

Accidental falls are a significant health risk to older adults, frequently leading to activity limitations and loss of independence. About $40 \%$ of adults aged $\geq 65$ years will fall at least once each year (Rubenstein ${ }^{32}$ ). Fall risk increases with age, and declining muscle function negatively affects one's ability to get up from a fall (Berg and Cassells ${ }^{5}$; Bergen ${ }^{6}$; Kim et $\mathrm{al}^{19}$ ).

Long lies, where a fall goes undetected and the individual is unable to get up on their own, can result in secondary complications, for example, dehydration, rhabdomyolysis, pressure sores, pneumonia, hypothermia, increased fear of
Copyright (๑) 2020 by the American Academy of Audiology. All rights reserved. Thieme Medical Publishers, Inc., 333 Seventh Avenue, New York, NY 10001 , USA.

Tel: +1(212) 760-0888.
DOI https://doi.org/ 10.3766/jaaa.19056. ISSN 1050-0545. 
falling, and death (Tinetti et $\mathrm{al}^{35}$; Fleming et $\mathrm{al}^{14}$ ). Lying on the floor, longer than an hour, has been associated with hospital admissions and subsequent moves into long-term care (Fleming et al ${ }^{14}$ ).

When initiated after a fall, personal emergency response systems (PERSs) are effective in preventing long lies. By contrast, long lies have been reported when individuals did not have a call alarm, had call alarms but were not wearing them, chose not to activate an alarm, or experienced difficulty activating the alarm (Fleming et $\mathrm{al}^{14}$ ). Personal injury, confusion, sensory impairments, and limitations with manual dexterity can also inhibit successful activations of the PERS.

To address these problems, the PERS can include a fall detection device (FDD) to automatically initiate an alert on behalf of the user. A variety of FDDs, including the one using a hearing aid with an embedded inertial sensor, have been previously used in research (Lindemann et $\mathrm{al}^{22}$; Bourke et $\mathrm{al}^{7}$ ). Common wearable FDDs include neck-worn pendants, smartphone apps, and wrist-worn devices (Aguiar et $\mathrm{al}^{2}$; Lipsitz et $\mathrm{al}^{23}$; Chaudhuri et $\mathrm{al}^{8}$ ). Others have used environmental sensors such as cameras or microphones to detect falls in fixed locations, for example, in the laboratory, within nursing facilities (Rougier et $\mathrm{al}^{31}$; Li et $\mathrm{al}^{20}$ ).

In real-world applications, PERS devices have been associated with age-based stereotypes, and environmental sensors have evoked privacy concerns (Demiris et $\mathrm{al}^{13}$ ). Individuals have acknowledged various psychosocial barriers to the PERS use, particularly before experiencing an injurious fall. Despite the report that only $9.7 \%$ of caregivers presently use monitoring technologies, many older adults are receptive to the concept of the PERS (Project Catalyst and HITLAB $^{26}$; Tinetti and $\mathrm{Kumar}^{34}$ ).

Individuals who might benefit from treatment in hearing clinics are at a greater risk of falling than their age-matched peers (Criter and Honaker ${ }^{12}$ ). Lin and Ferrucci ${ }^{21}$ reported a significant association between the severity of hearing impairment and reports of falls, even when adjusting for demographic, cardiovascular, and vestibular balance function. Numerous behavioral, physiological, and pathological mechanisms could underlie the reported associations between hearing impairment and falls, including comorbid vestibular, neural, or cardiovascular pathology; genetic influences; decreased awareness of the auditory environment; divided attentional resources for locomotion and maintenance of postural balance; and frailty which could be mediated through social isolation, depression, physical inactivity, and cognitive impairment (see Agmon et $\mathrm{al}^{1}$ for a review).

One possible solution to increase fall-detection-monitoring technology adoption may be to integrate FDDs into functional hearing instruments, which are less-conspicuous than other forms of FDDs, are commonly already being worn by individuals who are at risk for falling, and have become progressively less-stigmatized, wearable devices (Rauterkus and Palmer ${ }^{28}$; Chaudhuri et $\mathrm{al}^{8}$ ).

Falls are a leading cause of head injury, accounting for more than $80 \%$ of traumatic brain injury (TBI) among older adults (Ingebrigtsen et al ${ }^{17}$; Harvey and Close ${ }^{15}$ ). Reports of mild cognitive impairment or dementia were also signifi- cantly associated with fall-related TBI (Teo et $\mathrm{al}^{33}$ ). Headworn FDDs could be particularly adept at initiating an automated alert when a fall involves head impact, which would inherently increase the likelihood that a TBI, loss of consciousness, or confusion might preclude the fall victim from manually activating an alert system.

Furthermore, head-worn FDDs benefit from human biomechanics, which stabilize and protect the head during activities of daily living (ADLs) and falls. Because of their location and coupling to the ear, hearing instruments are naturally less susceptible to spurious movements than FDDs worn on the arm or hung around the neck (Cola et $\mathrm{al}^{11}$ ). The head-impact velocity is also a key metric for gauging severity of falls (Choi et $\mathrm{al}^{9}$ ). With the greatest falling distance and fewer motion artifacts to resolve, head-worn FDDs could potentially be tuned to capture a greater number of falls, with few false alarms.

The Livio AI (A) hearing instrument's fall detection algorithm was designed to be highly sensitive, even detecting falls, in training data, that could be characterized by slow vertical acceleration or low-impact magnitude. The Livio AI (B) hearing instrument's fall detection algorithm was designed to produce fewer false-positive detections by requiring more rapid vertical acceleration, a greater estimated falling distance, and more significant impact magnitudes.

Performance (i.e., accuracy, sensitivity, and specificity) of FDDs is an important consideration for potential users (Demiris et $\mathrm{al}^{13}$; Igual et $\mathrm{al}^{16}$ ). In our study, continuous inertial measurement unit (IMU) sensor data were recorded from hearing instruments, during trials of simulated falls, near-falls, and ADLs. The ear-level IMU recordings were then processed through firmware emulators, thereby permitting direct performance comparisons between two different hearing instrument-based fall detection systems.

Participants also wore a commonly used fall detection pendant as a predicate device for comparison. Previous studies have observed performance differences between FDDs evaluated inside versus outside of the laboratory (Bagala et $\mathrm{al}^{4}$; Kangas et $\mathrm{al}^{18}$ ). We selected the AutoAlert help button pendant as a performance reference, based on the device's existing classification by the US Food and Drug administration (FDA) and a large number of real-world users.

\section{Methods}

Data were collected at the Injury Prevention and Mobility Laboratory at Simon Fraser University. All participants provided written informed consent, and the study protocol was approved by the Research Ethics Board of Simon Fraser University.

The experimental design was informed by previously reported, laboratory-based falling experiments, where participants mimicked falling behaviors observable in videos of older adults who sustained real-life falls (Robinovitch et $\mathrm{al}^{30}$; Aziz et $\mathrm{al}^{3}$ ). Participants wore a commercially available, fall detection pendant and bilateral hearing instruments. The hearing instruments each contained an IMU sensor and had wireless streaming capability to send continuous IMU data to an accessory device (not worn by the participant) for storage. 
Participants simulated a variety of falls, near-falls, and ADLs. Three trials were acquired for each of eight types of falls, eight types of near-falls, and eight different types of ADLs. There were 24 conditions in total, which yielded a total of 72 trials for each participant. IMU data were collected from the hearing instruments along with the corresponding detection state of the fall detection pendant, as indicated by the light and alarm of the base-station unit associated with the fall detection pendant. All trials were video recorded.

\section{Participants}

Participants were recruited using flyers and email notifications to students at Simon Fraser University. A total of 10 healthy young adults ( 5 women) aged between 20 and 32 years participated in the study. Participants' ages, body weights, and heights averaged 23.8 years (standard deviation [SD] $=4.0), 70.1 \mathrm{~kg}(\mathrm{SD}=19.8)$, and $172.0 \mathrm{~cm}(\mathrm{SD}=10.2)$, respectively, as summarized in -Table 1 . Participants with a range of body types were recruited, as height and weight differences can affect the duration of vertical acceleration and the magnitudes of impact(s) when the individuals suffer falls. Individuals were excluded if they had recent selfreported concussions (within the last two years), cardiac disorders, bone fractures or joint sprains (within the previous six months), or any musculoskeletal conditions causing joint or soft tissue pain. All participants had normal $(n=4)$ or corrected-to-normal $(n=6)$ vision during testing.

\section{Equipment}

Participants wore an AutoAlert help button fall detection pendant (Model FD100; Philips Lifeline, Framingham, MA) and a binaural set of Livio AI behind-the-ear (BTE) hearing instruments (Starkey Hearing Technologies, Eden Prairie, MN).

The operation manual for the AutoAlert pendant states that it is a FDA Class II medical device intended for continuous operation as a PERS (Philips Lifeline ${ }^{25}$ ). The present authors assumed the performance of the test device was within the specification tolerances submitted to the FDA by the manufacturer.

The Livio AI BTE hearing instruments were manufactured with an IMU sensor integrated into each of the devices' flexible circuits. The hearing instruments were coupled to the participants' ears using preformed, thin tubes and open-fit earbuds; sound amplification, however, was not provided to the participants. The hearing instruments also contained a Bluetooth ${ }^{\circledR}$ low-energy radio with the capability of streaming continuous IMU data to an accessory device for storage. The IMU's accelerometer and gyroscope signals were each sampled at $104 \mathrm{~Hz}$.
The IMU data were postprocessed through a firmware emulation module that modeled two variants (i.e., A and B) of the Livio AI firmware. Outside of simulation, the accessory device is relied on to send alert notifications to other individuals, such as caregivers, when a fall is detected.

Fall and near-fall trials were simulated on padded surfaces, and participants wore a helmet for personal safety. The helmet did not cover participants' ears nor was the helmet permitted to contact the hearing instruments. Three helmet sizes were available, and the researchers ensured a snug fit to minimize any potential acceleration artifacts caused by protective equipment. For various trials, participants' gait was perturbed by either a moveable platform, an ankle tether, or by a nudge from a padded glove.

All trials were video recorded. Within the field-of-view of the camera, the videos include the participant undertaking the protocol, a clock showing time and date, and the PERS base unit, providing record of when falls were detected by the AutoAlert pendant. In accordance with instructions from the device's manufacturer, participants were not permitted to get up from a fall until enough time to register a detection had elapsed. Walking within $30 \mathrm{sec}$ after a fall event could errantly cancel notification of a detected fall (Philips Lifeline ${ }^{25}$ ).

\section{Motion Simulations}

Each participant experienced eight types of falls, eight types of near-falls, and performed eight different types of ADLs. Participants observed exemplary videos of real-life falls, which were used similarly in the previously reported investigation (Robinovitch et $\mathrm{al}^{30}$; Aziz et $\mathrm{al}^{3}$ ). During each trial, IMU data were simultaneously collected from the two hearing instruments. In addition, the detection state ofthe fall detection pendant was recorded for each trial. Participants systematically performed three trials for each condition, resulting in at least 72 trials per participant. Some participants inadvertently fell during near-fall trials; therefore, 15 more falls were collected than were prescribed by the study's protocol. To maintain an equal distribution of trials between participants and fall conditions, falls which occurred during intended near-fall trials were excluded from our analyses.

\section{Fall and Near-Fall Trials}

Falls and near-falls were simulated in a laboratory environment where appropriate participant protections could be provided. Some destabilizations were initiated autonomously by the participant, and others were initiated through various perturbations, as summarized in - Table 2. Participants were shown exemplary videos and given the opportunity to practice

Table 1 Mean \pm SD (and Range) in Participant Demographics

\begin{tabular}{|l|l|l|l|}
\hline & Male $(\mathbf{n}=\mathbf{5})$ & Female $(\mathbf{n}=\mathbf{5})$ & Combined $(\mathbf{n}=\mathbf{1 0})$ \\
\hline Age (years) & $24.0 \pm 4.7(20-32)$ & $23.6 \pm 3.7(21-30)$ & $23.8 \pm 4.0(20-32)$ \\
\hline Weight $(\mathrm{kg})$ & $83.2(67-103)$ & $57.0(45-78)$ & $70.1 \pm 19.8(45-103)$ \\
\hline Height $(\mathrm{cm})$ & $179.2 \pm 7.5(174-192)$ & $164.7 \pm 6.8(154-192)$ & $172.0 \pm 10.2(154-192)$ \\
\hline Handedness (R/L) & $4 \mathrm{R}, 1 \mathrm{~L}$ & $4 \mathrm{R}, 1 \mathrm{~L}$ & $8 \mathrm{R}, 2 \mathrm{~L}$ \\
\hline
\end{tabular}

Note: All demographic data were self-reported by participants. Handedness was based on the dominant hand while writing. 
Table 2 Summary of the Destabilization Techniques Used for each of the Fall and Near-Fall Trials Performed by Participants

\begin{tabular}{|l|l|}
\hline Condition & Cause of Destabilization \\
\hline Slip forward & Moving platform \\
\hline Slip backward & Moving platform \\
\hline Trip & $\begin{array}{l}\text { Ankle tether } \\
\text { while walking }\end{array}$ \\
\hline $\begin{array}{l}\text { Incorrect weight transfers } \\
\text { due to a misstep }\end{array}$ & Self-initiated \\
\hline $\begin{array}{l}\text { Incorrect weight transfer while } \\
\text { rising from sitting }\end{array}$ & Self-initiated \\
\hline $\begin{array}{l}\text { Incorrect weight transfer while } \\
\text { descending from standing }\end{array}$ & Self-initiated \\
\hline Hit or bumped & $\begin{array}{l}\text { Perturbed by a } \\
\text { padded object }\end{array}$ \\
\hline Loss of consciousness/collapse & Self-initiated \\
\hline
\end{tabular}

mimicry of the videos. Researchers provided feedback to the participants to improve the quality of simulations. If a destabilization caused any limb segment other than the participant's feet to contact the platform, the trial was considered a "fall."

Fall conditions were intended to result in a fall and were representative of the breadth of causes of older adult falls, including slips forward and backward, trips, bumps, and incorrect weight transfers while rising from sitting, while descending from standing, and due to missteps. Our selection of falls and near-falls tasks was informed by video analysis of actual falls that had occurred among older adults living in two, long-term care facilities located in Canada (Robinovitch et $\mathrm{al}^{30}$; Choi et $\mathrm{al}^{10}$ ). The protocol and participant instructions for each fall and near-fall condition are provided in -Appendix A. After landing, participants were instructed to remain lying on the platform for $35 \mathrm{sec}$; however, the participants were permitted to roll into a more comfortable resting position. All fall trials resulted in a fall.

The near-fall conditions were like fall conditions, except participants were instructed to attempt making a balance recovery instead of falling to the ground. Because near-fall trials were not intended to result in participants lying on the ground, there was no instruction to the participants to remain in place after recovering balance. Near-fall trials were repeated if the participant did not appear to have been destabilized enough to evoke a natural balance recovery reaction, such as rapid stepping. If the participant was unable to recover balance during a near-fall trial, the trial was repeated.

\section{ADL Trials}

Participants completed three trials for each of the eight ADL conditions, resulting in a total of 24 ADL trials. ADL conditions included normal walking, standing quietly, sitting down into a chair, lying down onto the ground, rising from sitting, picking an object up from the ground, and stair climbing. The protocol and participant instructions for
Table 3 Summary of the Prescribed Wait Periods for Each of the ADL Trials Performed by Participants

\begin{tabular}{|l|l|}
\hline Condition & Wait Period (sec) \\
\hline Normal walking & - \\
\hline Standing quietly & - \\
\hline $\begin{array}{l}\text { Descending from standing to } \\
\text { sitting on a chair }\end{array}$ & 35 \\
\hline $\begin{array}{l}\text { Descending from standing to } \\
\text { lying on the ground }\end{array}$ & 35 \\
\hline Rising from sitting to standing & - \\
\hline $\begin{array}{l}\text { Picking an object up from } \\
\text { the ground }\end{array}$ & - \\
\hline Ascending stairs & - \\
\hline Descending stairs & 35 \\
\hline
\end{tabular}

each ADL condition is provided in -Appendix B. Participants were instructed to undertake the ADLs at a "normal" (i.e., self-selected) pace and were only instructed to remain in place after three specific ADL conditions, as summarized in -Table 3. Trials were repeated if the participant deviated from instructions.

\section{Hearing Instrument Firmware Emulations}

Each of the hearing instruments had an algorithm that continuously monitored three-axis accelerometer signals from the embedded IMU. Monitoring these signals for a fall included classifying prefall motion activity, detecting the onset of a falling phase, detecting impacts, and evaluating postimpact activity. To do so, the hearing instrument's fall detection algorithm calculated various feature values from the motion data, such as vertical acceleration, estimated velocity, acceleration duration, estimated falling distance, posture changes, and impact magnitudes.

The hearing instrument-based fall detection system was designed to have a wireless, ear-to-ear link to exchange fall detection data between the two hearing instruments. Fall detection data from each hearing instrument were sent from one instrument to the other to compare the data and to provide redundancy for passing the combined data to an accessory device (i.e., smartphone).

Once detection data from at least one hearing instrument had been received by the accessory device, the accessory device performed a second-order analysis of the detection data. Consideration of binaural, fall detection data allowed the hearing instrument-based fall detection system to reject errant detections that might otherwise occur during certain types of nonfall activities, such as when one of the hearing instruments is being removed from the ear of the user. As emulated, the accessory device did not have access to any data which, theoretically, could have been obtained through sensors embedded directly into the accessory device.

Our methodology controlled for the variability between motion simulation trials and allowed for equitable comparisons of the two distinct hearing instrument-based fall detection systems (i.e., A and B). The same IMU data, 


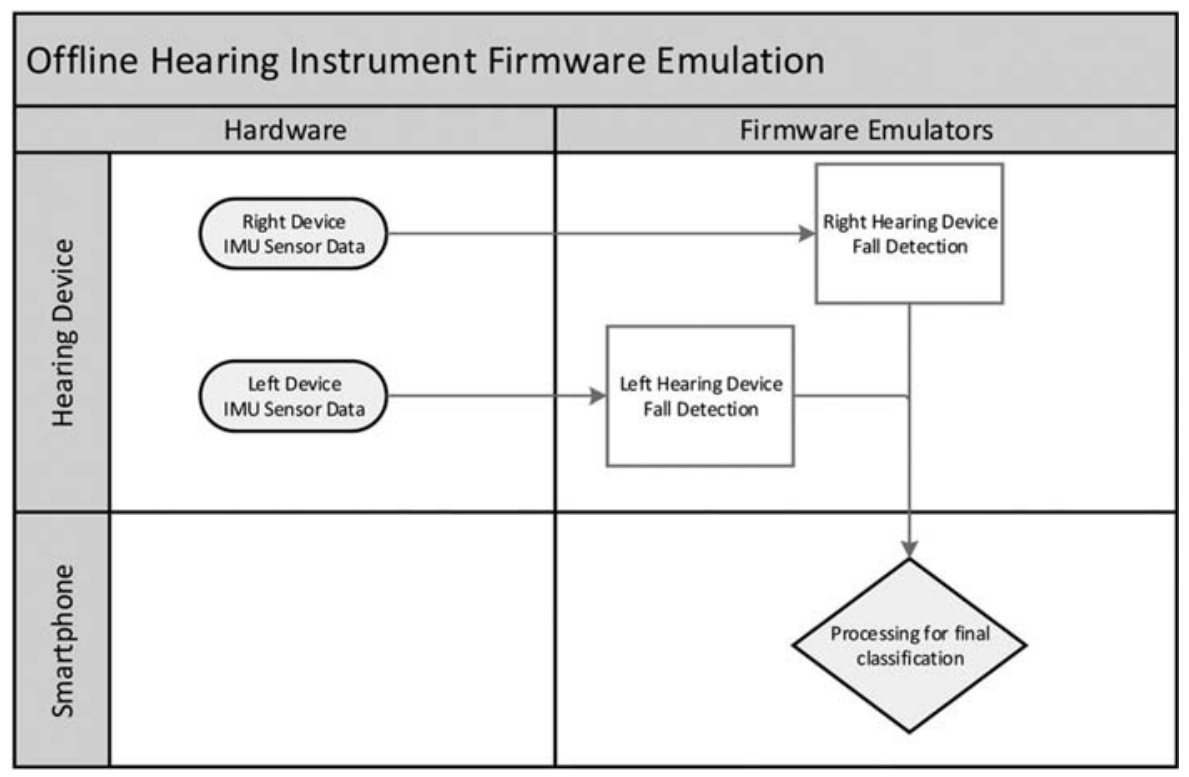

Fig. 1 Diagram of the offline evaluation of the hearing instrument-based fall detection system using firmware emulation.

recorded from the right-and left-side hearing instruments during the motion simulations, were processed through firmware emulation programs for each of the two hearing instrument-based fall detection systems. Firmware emulation programs were developed in MATLAB ${ }^{24}$ and precisely emulated the Livio AI fall detection systems, including a bilateral set of Starkey Livio AI i2400 BTE 13 hearing instruments "connected" to their companion, smartphone app, as depicted in - Figure 1. The detection state output, from the firmware emulation programs, was recorded for each of the fall, near-fall, and ADL trials.

\section{Performance Analyses}

Statistical analyses were performed in R statistical computing software ( $\mathrm{R}$ Core Team ${ }^{27}$ ). Detection-state outputs were analyzed to characterize the performance of the AutoAlert pendant and each of the two Livio AI system variants. Detection states were categorized as either "true positive," "true negative," "false positive (FP)," or "false negative." Sensitivity, specificity, and overall accuracy for each of the three systems being investigated were computed using the AUC function of the Psych package for R $\left(\right.$ Revelle $\left.^{29}\right)$.
Performance measures were calculated using the following formulae:

$$
\begin{gathered}
\text { Sensitivity }=\frac{\text { True Positives }}{\text { True Positives + False Negatives }} \times 100 \%, \\
\text { Specificity }=\frac{\text { True Negatives }}{\text { True Negatives + False Positives }} \times 100 \%, \text { and } \\
\text { Accuracy }=
\end{gathered}
$$

\section{Results}

Performance measures of each of the fall detection systems are summarized in - Table 4 . During the participants' motion simulations, the AutoAlert pendant detected the event of a fall during 198 of the 240 fall trials, yielding a true-positive (i.e., sensitivity) rate of $82.5 \%$. AutoAlert did not produce any FPs during the 240 ADL trials, but it did produce one FP during the 240 near-fall trials, yielding a true-negative (i.e., specificity) rate of $99.8 \%$. The overall accuracy of the AutoAlert pendant was $94.0 \%$ for the 720 motion simulations.

The Livio AI (A) hearing instrument-based fall detection system detected the event of a fall during 221 of the 240 fall trials, yielding a sensitivity rate of $92.1 \%$. Livio AI (A) did not produce any FPs during the $240 \mathrm{ADL}$ trials, but the system did

Table 4 Sensitivity and Specificity Rates of the AutoAlert Pendant and Each Variant of the Livio Al Hearing Instrument-based Fall Detection System, across All Participants and Trials

\begin{tabular}{|l|l|l|l|l|}
\hline & No. of Trials & AutoAlert Pendant & Livio Al (A) & Livio Al (B) \\
\hline True-positive falls (sensitivity rate) & 240 & $198(82.5 \%)$ & $221(92.1 \%)$ & $192(80.0 \%)$ \\
\hline False-positive falls (specificity rate) & 480 & $1(99.8 \%)$ & $6(98.8 \%)$ & $1(99.8 \%)$ \\
\hline ADLs & 240 & $0(0.0 \%)$ & $0(0.0 \%)$ & $0(0.0 \%)$ \\
\hline Near-falls & 240 & $1(99.6 \%)$ & $6(97.5 \%)$ & $1(99.6 \%)$ \\
\hline Accuracy: falls and ADLs & 480 & $438(91.3 \%)$ & $461(96.0 \%)$ & $432(90.0 \%)$ \\
\hline Accuracy: falls, near-falls, and ADLs & 720 & $677(94.0 \%)$ & $695(96.5 \%)$ & $671(93.2 \%)$ \\
\hline
\end{tabular}

Note: A total of 240 trials took place for each of falls, near-falls, and ADLs. 
produce six FPs during the 240 near-fall trials, yielding a specificity rate of $98.8 \%$. The overall accuracy of the Livio AI (A) hearing instrument-based fall detection system was $96.5 \%$ for the 720 motion simulations.

We compared accuracy, sensitivity, and specificity across the three fall detection systems with McNemar's test for paired nominal data. Livio AI (A) was more accurate than AutoAlert $\left[\mathrm{X}_{(1)}^{2}=9.13, p=0.002\right]$ and Livio AI (B) $\left[\mathrm{X}_{(1)}^{2}=27.03\right.$, $p<0.001$ ]; the difference in accuracy between Livio AI (B) and AutoAlert was not significant $\left[\mathrm{X}_{(1)}^{2}=0.36, p=0.550\right]$.

Livio AI (A) was significantly more sensitive than AutoAlert $\left[X_{(1)}^{2}=9.98, p=0.002\right]$ and Livio $\mathrm{AI}(\mathrm{B})\left[\mathrm{X}_{(1)}^{2}=29.00\right.$, $p<0.001]$; the difference in sensitivity between Livio AI (B) and AutoAlert was not significant $\left[X_{(1)}^{2}=0.51, p=0.47\right]$.

Livio AI (B) was significantly more specific than Livio AI (A) $\left[\mathrm{X}_{(1)}^{2}=4.00, p=0.045\right]$. However, specificity differences were not statistically significant between Livio AI (A) and AutoAlert $\left[\mathrm{X}_{(1)}^{2}=3.57, p=0.059\right]$ or between Livio AI (B) and AutoAlert $\left[\mathrm{X}_{(1)}^{2}=1.00, p=0.317\right]$.

- Table 5 provides a summary of each system's sensitivity rate, calculated for each of the various fall conditions.

\section{Discussion}

The goal of this experiment was to evaluate the accuracy of several variants of a hearing instrument-based fall detection system. We hypothesized that hearing instruments could perform automatic fall detection more accurately than devices worn on other parts of the body. On average, the sensitivity of the Livio AI (A) hearing instrument-based fall detection system was 9.6 percentage-points higher than that of the fall detection pendant, and neither devices produced a false-positive detection during ADL trials.

The authors acknowledge several limitations of the present study, including the decision to use young healthy adult participants who had no known hearing loss, history of falls, or balance impairment. In addition, the present study assumed perfect wireless connectivity between devices during our firmware emulations (e.g., between the hearing instruments and the accessory device). This study also did not investigate real-world use patterns of the hearing instruments by older adults, who may fail to wear the devices during some risky behaviors, such as nocturnal walking or while bathing.

As our decision to systematically simulate falls and daily activities was well intentioned, it may explain the high degree of accuracy observed for the three fall detection systems. Although our simulations were modeled from videos of falls occurring in nursing facilities, our simulations did not include all imaginable types of falls. For example, we did not simulate falls down stairways or from chairs, ladders, and bicycles. Future work could explore the performance of FDDs, ecologically, with adults who have an elevated risk for falling. Future work could also explore the behavioral effects of adding fall detection capabilities to hearing instruments.

As previously discussed, few caregivers reported using the commonly available monitoring technologies despite their apparent benefits, when activated after a fall (Fleming et $\mathrm{al}^{14}$; Project Catalyst and $\mathrm{HITLAB}^{26}$ ). Automatic FDDs can help overcome some of the challenges that might prevent a user from successfully activating a notification alert to others. For some individuals, a hearing instrument-based fall detection system may be more convenient or carry less stigma than traditional PERS devices; this may alleviate some of the psychosocial barriers to using FDDs and the problem of not having an alerting system available when a fall occurs (Chaudhuri et $\mathrm{al}^{8}$ ). Future work could also explore fall detection hearing instrument adoption and the potential that use thereofmight reduce the risk of long lies after falls.

Each of the FDDs compared in this study performed perfectly during the ADL in the present study. The hearing instrument-based fall detection systems each produced a slightly higher false-positive rate than the fall detection pendant, during trials where the participants began to fall but recovered their balance before reaching the ground. One of the two hearing instrument-based fall detection systems was able to detect more ofthe falls than the fall detection pendant and was an overall more accurate FDD than the fall detection pendant. Individuals who consistently wear

Table 5 Breakdown of Sensitivity Rates of the AutoAlert Pendant and Each Variant of the Livio Al Hearing Instrument-based, Fall Detection System during Each Fall Condition

\begin{tabular}{|l|l|l|l|}
\hline Fall Type & AutoAlert Pendant (\%) & Livio Al (A) (\%) & Livio Al (B) (\%) \\
\hline Backward slip & 93.3 & 96.7 & 96.7 \\
\hline Forward Slip & 53.3 & 90.0 & 86.7 \\
\hline Trip & 66.7 & 100 & 93.3 \\
\hline Incorrect transfer due to misstep & 73.3 & 93.3 & 70.0 \\
\hline Incorrect transfer during rising from sitting & 93.3 & 93.3 & 80.0 \\
\hline Incorrect transfer during descending from standing & 96.7 & 90.0 & 73.3 \\
\hline Hit or bump & 86.7 & 86.7 & 63.3 \\
\hline Loss of consciousness or lower limb collapse & 96.7 & 86.7 & 76.7 \\
\hline Mean \pm SD & $82.5 \pm 16.2$ & $92.1 \pm 4.7$ & $80.0 \pm 11.5$ \\
\hline Range & $53.3-96.7$ & $86.7-100$ & $63.3-96.7$ \\
\hline
\end{tabular}

Note: A total of 30 trials took place for each of the fall conditions. 
hearing instruments with embedded FDDs may benefit from preventing long lies because it has been shown that this type of device is accurate in detecting falls and may be a suitable alternative compared with more traditional forms of FDDs (e.g., pendants, wrist-worn devices, etc.).

\section{Abbreviations}

$\begin{array}{ll}\text { ADLs } & \text { activities of daily living } \\ \text { BTE } & \text { behind the ear } \\ \text { FDA } & \text { US Food and Drug Administration } \\ \text { FDD } & \text { fall detection device } \\ \text { FP } & \text { false positive } \\ \text { IMU } & \text { inertial measurement unit } \\ \text { PERS } & \text { personal emergency response system } \\ \text { SD } & \text { standard deviation } \\ \text { TBI } & \text { traumatic brain injury }\end{array}$

\section{Funding}

This study received financial support from Starkey Hearing Technologies.

\section{Conflict of Interest \\ None declared.}

\section{Acknowledgments}

We graciously thank the research participants and the students at the Simon Fraser University for their generous time. We especially thank Brigitte Potvin and Vicki Komisar for assisting us with data collection and Dr. Stephen Robinovitch for sharing his technical expertise, overseeing our data collection, and for allowing us to use his laboratory space for this investigation.

\section{References}

1 Agmon M, Lavie L, Doumas M. The association between hearing loss, postural control, and mobility in older adults: a systematic review. J Am Acad Audiol 2017;28:575-588

2 Aguiar B, Rocha T, Silva J, Sousa IAccelerometer-based fall detection for smartphones. In: 2014 IEEE International Symposium on Medical Measurements and Applications (MeMeA). Lisboa, Portugal, pp. 1-6. doi: 10.1109/MeMeA.2014.6860110

3 Aziz O, Park EJ, Mori G, Robinovitch SN. Distinguishing the causes of falls in humans using an array of wearable tri-axial accelerometers. Gait Posture 2014;39:506-512

4 Bagala F, Becker C, Cappello A, Chiari L, Aminian K, Hausdorff JM, Zijlstra W, Klenk J. Evaluation of accelerometer-based fall detection algorithms on real-world falls. PLoS One 2012;07:e37062

5 Berg R, Cassells J, eds. Falls in older persons risk factors and prevention. In: Second Fifty Years: Promoting Health and Preventing Disability. Washington, DC: National Academies Press; 1992: 263-290. https://www.ncbi.nlm.nih.gov/books/NBK235613/. Accessed February 2, 2019.

6 Bergen G, Stevens MR, Burns ER. Falls and fall injuries among adults aged $\$ 65$ years-United States, 2014. MMWR Morb Mortal Wkly Rep 2016;65:993-998

7 Bourke AK, van de Ven P, Gamble M, O' Connor R, Murphy K, Bogan E, McQuade E, Finucane P, ÓLaighin G, Nelson J. Evaluation of waist-mounted tri-axial accelerometer based fall-detection algorithms during scripted and continuous unscripted activities. J Biomech 2010;43:3051-3057
8 Chaudhuri S, Kneale L, Le T, Phelan E, Rosenberg D, Thompson H, Demiris G. Older adults' perceptions of fall detection devices. J Appl Gerontol 2017;36:915-930

9 Choi WJ, Robinovitch SN, Ross SA, Phan J, Cipriani D. Effect of neck flexor muscle activation on impact velocity of the head during backward falls in young adults. Clin Biomech 2017;49:28-33

10 Choi WJ, Wakeling JM, Robinovitch SN. Kinematic analysis of video-captured falls experienced by older adults in long-term care. J Biomech 2015;48:911-920

11 Cola G, Avvenuti M, Piazza P, Vecchio A. Fall detection using a head-worn barometer. In: Perego P, Andreoni G, Rizzo G, eds. Vol. 192. Wireless Mobile Communication and Healthcare. Heidelberg, Germany: Springer International Publishing; 2017:217-224

12 Criter RE, Honaker JA. Audiology patient fall statistics and risk factors compared to non-audiology patients. Int J Audiol 2016; 55:564-570

13 Demiris G, Hensel BK, Skubic M, Rantz M. Senior residents' perceived need of and preferences for "smart home" sensor technologies. Int J Technol Assess Health Care 2008;24:120-124

14 Fleming J, Brayne C; Cambridge City over-75s Cohort (CC75C) Study Collaboration. Inability to get up after falling, subsequent time on floor, and summoning help: prospective cohort study in people over 90. BMJ 2008;337:a2227

15 Harvey LA, Close JCT. Traumatic brain injury in older adults: characteristics, causes and consequences. Injury 2012;43:18211826

16 Igual R, Medrano C, Plaza I. Challenges, issues and trends in fall detection systems. Biomed Eng Online 2013;12:66

17 Ingebrigtsen T, Mortensen K, Romner B. The epidemiology of hospital-referred head injury in Northern Norway. Neuroepidemiology 1998;17:139-146

18 Kangas M, Vikman I, Nyberg L, Korpelainen R, Lindblom J, Jamsa T. Comparison of real-life accidental falls in older people with experimental falls in middle-aged test subjects. Gait Posture 2012;35:500-505

19 Kim H, Hirano H, Edahiro A, Ohara Y, Watanabe Y, Kojima N, Kim M, Hosoi E, Yoshida Y, Yoshida H, Shinkai S. Sarcopenia: prevalence and associated factors based on different suggested definitions in community-dwelling older adults. Geriatr Gerontol Int 2016;16:110-122

20 Li Y, Zeng Z, Popescu M, Ho KC. Acoustic fall detection using a circular microphone array. Conf Proc IEEE Eng Med Biol Soc 2010; 2010:2242-2245

21 Lin FR, Ferrucci L. Hearing loss and falls among older adults in the United States. Arch Intern Med 2012;172:369-371

22 Lindemann U, Hock A, Stuber M, Keck W, Becker C. Evaluation of a fall detector based on accelerometers: a pilot study. Med Biol Eng Comput 2005;43:548-551

23 Lipsitz LA, Tchalla AE, Iloputaife I, Gagnon M, Dole K, Su ZZ, Klickstein L. Evaluation of an automated falls detection device in nursing home residents. J Am Geriatr Soc 2016;64:365-368

24 MATLAB. version 9.4 (R2018a). Natick, MA: The MathWorks Inc.; 2018

25 Philips Lifeline. Philips Lifeline AutoAlert Help Button: Instructions for Use. Rev 07. Framingham, MA: Philips Lifeline; 2013

26 Project Catalyst and HITLAB. Designing Technology for Caregivers: Understanding What Works and Doesn't. AARP Research. 2018. https://www.aarp.org/research/topics/care/info-2018/designing-technology-caregivers.html. Accessed November 9, 2018

27 R Core Team. R: A Language and Environment for Statistical Computing; Vienna, Austria: R Foundation for Statistical Computing; 2018. https://www.R-project.org/. Accessed April 9, 2019

28 Rauterkus EP, Palmer CV. The hearing aid effect in 2013. J Am Acad Audiol 2014;25:893-903

29 Revelle W. psych: Procedures for Psychological, Psychometric, and Personality Research. Evanston, IL: Northwestern University; 2018. https://CRAN.R-project.org/package=psych. Accessed April 9, 2019 
400 Automatic Fall Detection Burwinkel et al.

30 Robinovitch SN, Feldman F, Yang Y, Schonnop R, Leung PM, Sarraf T, Sims-Gould J, Loughin M. Video capture of the circumstances of falls in elderly people residing in long-term care: an observational study. Lancet 2013;381:47-54

31 Rougier C, Meunier J, St-Arnaud A, Rousseau J. Fall detection from human shape and motion history using video surveillance. 21st International Conference on Advanced Information Networking and Applications Workshops (AINAW'07), Niagara Falls, Ontario, Canada, Vol. 2, 2007;02:875-880
32 Rubenstein LZ. Falls in older people: epidemiology, risk factors and strategies for prevention. Age Ageing 2006;35(02):ii37-ii41

33 Teo DB, Wong HC, Yeo AW, Lai YW, Choo EL, Merchant RA. Characteristics of fall-related traumatic brain injury in older adults. Intern Med J 2018;48:1048-1055

34 Tinetti ME, Kumar C. The patient who falls: "It's always a tradeoff." JAMA 2010;303:258-266

35 Tinetti ME, Liu W-L, Claus EB. Predictors and prognosis of inability to get up after falls among elderly persons. JAMA 1993;269:65-70 


\begin{tabular}{|l|}
\hline Condition \\
\hline Slips (forward and backward) - \\
\hline Participants stood on a padded platform, which translated \\
forward or backward rapidly, inducing a backward and \\
forward fall, respectively. \\
The sequence of testing was randomized, with the excep- \\
tion of the first trial, which always consisted of a backward \\
slip. \\
Both forward slips and backward slips were collected (three \\
trials each).
\end{tabular}

Instructions to Participants

Trips -

Participants walked forward from one end of the padded platform toward the other end and were tripped during their walk by a tether attached at the ankle. To the participant, the tether suddenly became caught and then released, invoking the trip. Participants had ankle cuffs on both ankles so that the tripping leg was randomized without their knowledge.

Incorrect transfer due to a misstep -

Participants walked from one end of the platform toward the other. The participants deliberately induced imbalance, leading to a forward and sideways fall, by taking a step that has too small of a step length (approximately one half the length of previous steps).

This type of fall involved video mimicry to have the participant simulate a typical fall of this type in older adults. Before each trial, participants watched a video of a representative real-life fall by an older adult.

Incorrect transfer while rising from sitting -

Participants attempted to rise from sitting on a chair, lost balance while rising, and fell sideways.

This type of fall involved video mimicry to have the participant simulate a typical fall of this type in older adults. Before each trial, participants watched a video of a repre"Try to maintain your balance when the platform moves. However, should you fall, remain lying on the platform until we tell you to get back up."

In the event that the participant was able to maintain balance, we changed the instruction to "Avoid trying to recover balance."

sentative real-life fall by an older adult.

Incorrect transfer while descending from standing -

Participants simulated the act of sitting down on a foam chair from an initial standing position, and missing the chair and falling backward.

This type of fall involved video mimicry to have the participant simulate a typical fall of this type in older adults. Before each trial, participants watched a video of a representative real-life fall by an older adult.

"Try to maintain your balance. However, should you fall, remain lying on the platform until we tell you to get back up." In the event that the participant was able to maintain balance, we changed the instruction to "Avoid trying to recover balance."

Hit or bump -

Participants stood on the platform while weight shifting and were pushed by a padded glove held by one of the investigators, leading to imbalance and a sideways fall. This type of fall involved video mimicry to have the participant simulate a typical fall of this type in older adults. Before each trial, participants watched a video of a representative real-life fall by an older adult.

"Act out the fall you see on the video, including the nature of imbalance leading to falling, and the resulting movements of the body during the fall. When you land on the platform, please remain lying down until we tell you to get back up."

Loss of consciousness/collapse -

Participant simulated a fall due to loss of consciousness (fainting) from a standing position.

This type of fall involved video mimicry to have the participant simulate a typical fall of this type in older adults. Before each trial, participants watched a video of a representative real-life fall by an older adult.

"Act out the fall you see on the video, including the nature of imbalance leading to falling, and the resulting movements of the body during the fall. When you land on the platform, please remain lying down until we tell you to get back up."

"Act out the fall you see on the video, including the nature of imbalance leading to falling, and the resulting movements of the body during the fall. When you land on the platform, please remain lying down until we tell you to get back up."

"Act out the fall you see on the video, including the nature of imbalance leading to falling, and the resulting movements of the body during the fall. When you land on the platform, please remain lying down until we tell you to get back up." 
Appendix A (Continued)

\begin{tabular}{|c|c|}
\hline Condition & Instructions to Participants \\
\hline \multicolumn{2}{|l|}{ Slips (forward and backward) - } \\
\hline $\begin{array}{l}\text { Participants stood on a padded platform, which translated } \\
\text { forward or backward rapidly, inducing a backward and } \\
\text { forward fall, respectively. } \\
\text { The sequence of testing was randomized, with the exception } \\
\text { of the first trial, which always consisted of a backward slip. } \\
\text { Both forward slips and backward slips were collected (three } \\
\text { trials each). }\end{array}$ & $\begin{array}{l}\text { "Try to maintain your balance when the platform moves. } \\
\text { However, should you fall, remain lying on the platform until } \\
\text { we tell you to get back up." } \\
\text { In the event that the participant was able to maintain balance, } \\
\text { we changed the instruction to "Avoid trying to recover } \\
\text { balance." }\end{array}$ \\
\hline
\end{tabular}

\section{Appendix B}

\begin{tabular}{|c|c|}
\hline Condition & Instructions to Participants \\
\hline \multicolumn{2}{|l|}{ Normal Walking - } \\
\hline $\begin{array}{l}\text { Participants walked around the basement of Simon Fraser } \\
\text { University's Science Building. They started at the laboratory } \\
\text { and walked through an 8-shaped course. The course was set } \\
\text { up to allow for reasonable bouts of gait in a straight line, as } \\
\text { well as left- and right-hand turns. } \\
\text { A researcher accompanied and directed participants while } \\
\text { walking. The researcher walked slightly behind participants to } \\
\text { avoid affecting the participant's walking pace. }\end{array}$ & $\begin{array}{l}\text { "Please walk along the course, as directed by the researcher } \\
\text { with you. Walk at a regular and comfortable pace for you." }\end{array}$ \\
\hline \multicolumn{2}{|l|}{ Standing quietly - } \\
\hline $\begin{array}{l}\text { Participants stood erect, with their arms at their sides, for } 20 \text { - } \\
\text { sec trials inside the laboratory. }\end{array}$ & $\begin{array}{l}\text { "Please stand quietly with your arms at your sides, for about } \\
20 \mathrm{sec} \text {. A researcher will tell you when you can relax." }\end{array}$ \\
\hline \multicolumn{2}{|l|}{ Descending from standing to sitting on a chair- } \\
\hline $\begin{array}{l}\text { Participants walked two to three steps toward a chair then sat } \\
\text { down and remained in place for } 35 \mathrm{sec} \text {. }\end{array}$ & $\begin{array}{l}\text { "Please sit down on the chair, at a regular and comfortable } \\
\text { pace for you. Please remain seated until we tell you that you } \\
\text { can get back up." } \\
\text { No instructions were given with respect to how participants } \\
\text { use their upper limbs or aspects of the chair during descent. }\end{array}$ \\
\hline \multicolumn{2}{|l|}{ Descending from standing to lying on the ground - } \\
\hline $\begin{array}{l}\text { Participants stood erect on the motion platform, and then } \\
\text { descended into lying on the platform. They remained in place } \\
\text { for } 35 \mathrm{sec} \text {. }\end{array}$ & $\begin{array}{l}\text { "Please lie down on the platform, at a regular and comfortable } \\
\text { pace for you. Try to avoid jumping or falling as you lie down. } \\
\text { Please remain lying down until we tell you that you can get } \\
\text { back up." } \\
\text { No further instructions were given with respect to the } \\
\text { individual descent strategy. }\end{array}$ \\
\hline \multicolumn{2}{|l|}{ Rising from sitting to standing - } \\
\hline Participants sat on a chair, and then rose to standing height. & $\begin{array}{l}\text { "Please stand up from the chair, at a regular and comfortable } \\
\text { pace for you." } \\
\text { No further instructions were given with respect to the ascent } \\
\text { strategy. }\end{array}$ \\
\hline \multicolumn{2}{|l|}{ Picking an object from the ground - } \\
\hline $\begin{array}{l}\text { Participants stood erect with their arms at their sides, and a } \\
\text { pen was placed on the floor a few feet away Participants took } \\
\text { two to three steps, picked up the pen from the ground, and } \\
\text { placed it on a nearby table. The table served as an implicit cue } \\
\text { for the participants to return to the standing height. This task } \\
\text { took place inside the laboratory. }\end{array}$ & $\begin{array}{l}\text { "Please pick up the pen that is currently in front of you, and } \\
\text { place it on the table beside you. Do this at a regular and } \\
\text { comfortable pace. Feel free to step or turn around if you } \\
\text { would like." } \\
\text { No further instructions were given with respect to the } \\
\text { descent, ascent, reaching, grasping, or prehension strategy }\end{array}$ \\
\hline \multicolumn{2}{|l|}{ Ascending stairs - } \\
\hline $\begin{array}{l}\text { Participants walked up the stairs adjacent to the laboratory at } \\
\text { Simon Fraser University. }\end{array}$ & $\begin{array}{l}\text { "Please walk up the stairs to the main floor of the building, at a } \\
\text { regular and comfortable pace for you. Take the steps one at a } \\
\text { time, and try not to run." } \\
\text { No further instructions were given with respect to the ascent }\end{array}$ \\
\hline
\end{tabular}


Appendix B (Continued)

\begin{tabular}{|c|c|}
\hline Condition & Instructions to Participants \\
\hline & $\begin{array}{l}\text { strategy, including handrail use. Trials were repeated if par- } \\
\text { ticipants skipped steps, for consistency with other stair gait } \\
\text { studies. }\end{array}$ \\
\hline \multicolumn{2}{|l|}{ Descending stairs - } \\
\hline $\begin{array}{l}\text { Participants walked down the stairs adjacent to the laboratory } \\
\text { at Simon Fraser University. They remained in place for } 35 \mathrm{sec} \\
\text { at the bottom of the staircase. }\end{array}$ & $\begin{array}{l}\text { "Please walk down the stairs to the main floor of the building, } \\
\text { at a regular and comfortable pace for you. Take the steps one } \\
\text { at a time, and try not to run. Please stand still at the bottom of } \\
\text { the staircase until we tell you that you can move." } \\
\text { No further instructions were given with respect to the descent } \\
\text { strategy, including handrail use. Trials were repeated if par- } \\
\text { ticipants skipped steps, for consistency with other stair gait } \\
\text { studies. }\end{array}$ \\
\hline
\end{tabular}

